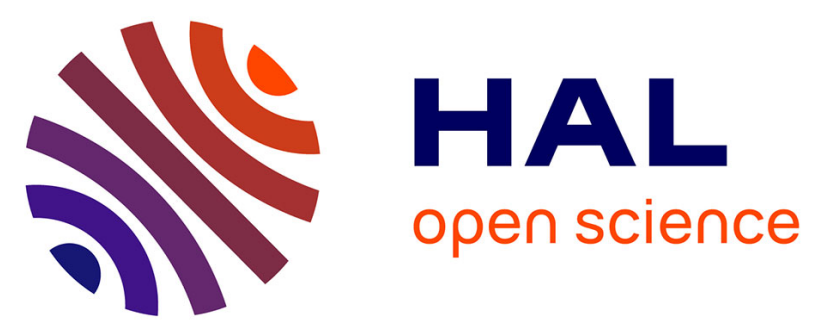

\title{
Quantitative Error Analysis in Near-Field Scanning Microwave Microscopy
}

Kamel Haddadi, Petr Polovodov, Didier Theron, Gilles Dambrine

\section{To cite this version:}

Kamel Haddadi, Petr Polovodov, Didier Theron, Gilles Dambrine. Quantitative Error Analysis in Near-Field Scanning Microwave Microscopy. 2018 International Conference on Manipulation, Automation and Robotics at Small Scales (MARSS), Jul 2018, Nagoya, Japan. 10.1109/MARSS.2018.8481160 . hal-01913677

\section{HAL Id: hal-01913677 \\ https://hal.science/hal-01913677}

Submitted on 6 Nov 2018

HAL is a multi-disciplinary open access archive for the deposit and dissemination of scientific research documents, whether they are published or not. The documents may come from teaching and research institutions in France or abroad, or from public or private research centers.
L'archive ouverte pluridisciplinaire HAL, est destinée au dépôt et à la diffusion de documents scientifiques de niveau recherche, publiés ou non, émanant des établissements d'enseignement et de recherche français ou étrangers, des laboratoires publics ou privés. 


\title{
Quantitative Error Analysis in Near-Field Scanning Microwave Microscopy
}

\author{
Kamel Haddadi, Petr Polovodov, Didier Théron and Gilles Dambrine \\ University Lille, CNRS, UMR 8520 - IEMN \\ F-59000 Lille, France \\ kamel.haddadi@univ-lille1.fr
}

\begin{abstract}
Near-field scanning microwave microscopy (NSMM) has to face several issues for the establishment of traceable and quantitative data. In particular, at the nanoscale, the wavelength of operation in the microwave regime appears disproportionate compared to the size of the nano-object under investigation. Incidentally, the microwave characterization results in poor electrical sensitivity as the volume of the wave/material interaction is limited to a fraction of the wavelength. In addition, the definition of nanoscale microwave impedance standards requires accurate knowledge of the material and dimensional properties at such scale. In this effort, a quantitative error analysis performed on micrometric metal oxide semiconductor (MOS) structures is proposed. In particular, atomic force microscopy (AFM) image together with the magnitude and phase-shift images of the complex microwave reflection coefficient using a Keysight ${ }^{\mathrm{TM}}$ 's LS5600 AFM interfaced directly with a vector network analyzer, without electrical matching strategy, are performed around $9.5 \mathrm{GHz}$. From a detailed analysis of the raw data, completed with a FEMbased electromagnetic modeling, quantitative capacitances extraction and system limitations are exemplary shown.
\end{abstract}

Keywords-near-field scanning microwave microscopy (NSMM), vector network analyzer (VNA), metal oxide semiconductor (MOS), vector calibration.

\section{INTRODUCTION}

The introduction of scanning microwave microscopy (SMM) tools have pioneered many applications, notably including mapping and quantitative measurement of the electrical properties of materials and devices at micro and nano scale [1]-[5]. Basically, the scanning microwave microscope (SMM) consists of an atomic or scanning tunneling microscope combined with a vector network analyzer (VNA) [6]-[8]. The tip scans across the sample, emitting a microwave signal scattered by the material, altering its amplitude or/and phase properties.

The main difficulty of NSMM methods lies in the measurement traceability. Indeed, as such nanoscale, several sources of errors affect the measurement accuracy rendering the data interpretation and incidentally the establishment of quantitative results difficult [9]-[12]. First, there is a natural mismatch between the size of nanodevices and the wavelength of operation in the order of the $\mathrm{cm}$ in the microwave regime. Consequently, the electrical sensitivity of the microwave signal of interest, i.e. the reflected wave at the tip/sample interface, is limited by many factors such as parasitic capacitance of the body cantilever, non-systematic errors inherent to the VNA (source phase noise, IQ receiver noise, limitation of the analog-to-digital conversion), environment variations (temperature, hygrometry). In addition, the probe tip deteriorates during scanning operation leading to noncontrolled electrical imaging resolution.

The objective of this work is to provide a detailed analysis of the factors impacting the measurement quality. A verification kit developed by Keysight $^{\mathrm{TM}}$ and MC2Technologies $^{\mathrm{TM}}$ that consists of MOS capacitors is used for the experiments. This latter has found wide acceptance by the NSMM community and it thus constitutes an excellent test vehicle for further inter-comparison campaigns. In Section II, a measurement set-up using a direct connection between the AFM and the vector network analyzer is proposed to yield the intrinsic electrical sensitivity/accuracy. In addition, the capacitances verification kit is presented with a tentative FEM-based electromagnetic modeling. AFM and SMM imaging is discussed in Section III. The microwave images of the magnitude and phase-shift of the reflection coefficient are analyzed. A calibration modeling is proposed for the determination of the capacitance values using a modified Short-Open-Load (SOL) calibration method.

\section{MATERIALS AND METHODS}

The set-up of the NSMM consists of a Keysight ${ }^{\mathrm{TM}}$ LS5600 AFM interfaced with a Keysight ${ }^{\mathrm{TM}}$ PNA series network analyzer E8362B [11].

The verfication kit used here was developed by Keysight ${ }^{\mathrm{TM}}$ and MC2-Technologies ${ }^{\mathrm{TM}}$. It consists of MOS capacitors the values of which range from $0.1 \mathrm{fF}$ to $4 \mathrm{fF}$. The MOS capacitors are composed of circular gold electrodes evaporated on silicon dioxide deposited on a P-type silicon substrate of resistivity $1-3 \Omega \mathrm{cm}$. The calibration kit is depicted in Fig. 1. In order to vary the capacitances values, the diameter of the upper gold pad varies from 1 to $4 \mu \mathrm{m}$ and the $\mathrm{SiO}_{2}$ thickness ranges from 50 to $300 \mathrm{~nm}$ with about $80 \mathrm{~nm}$ steps. 


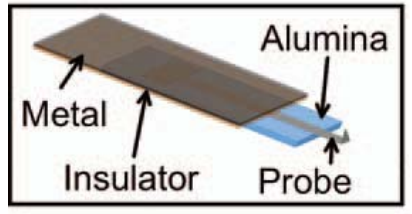

(a)
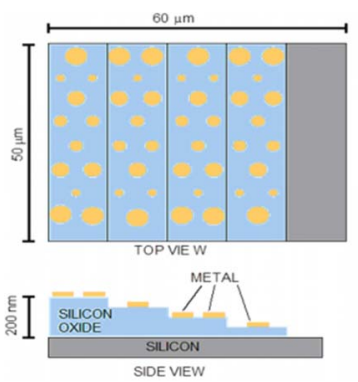

(b)
Fig. 1. (a) $\mathrm{RMN} \circledast \mathrm{SMM}$ probe. (b) Verification kit based on scaled MOS capacitances.

The impedance of the MOS structures measured at the tip apex of the probe is modeled by a series model consisting of an oxide capacitance $C_{\text {ox }}$ and a depletion capacitance $C_{\text {depl }}$. Both capacitances can be described by the parallel plate capacitor formalism. The resulting capacitance $C_{\text {Tот }}$ is given by

$$
C_{\mathrm{TOT}}=C_{\mathrm{ox}} C_{\mathrm{depl}} /\left(C_{\mathrm{ox}}+C_{\mathrm{depl}}\right)
$$

The capacitance $C_{\mathrm{ox}}$ is calculated from the areas of the gold pads $A$ and the $\mathrm{SiO}_{2}$ thicknesses $d_{\text {ox }}$.

$$
C_{o x}=A \frac{\varepsilon_{0} \varepsilon_{r S i O_{2}}}{d_{o x}}
$$

The silicon dioxide is assumed to have a relative dielectric constant of $\varepsilon_{\mathrm{rSi}_{2}}=3.9$. The thickness and areas of the capacitors were estimated from the AFM topography measurements [Fig. 2(b)] to take into account any deviations in geometry induced by the fabrication process of the calibration kit. The measured thicknesses $d_{\text {ox }}$ of the $\mathrm{SiO}_{2}$ layers were $41 \mathrm{~nm}, 127 \mathrm{~nm}, 220 \mathrm{~nm}$, and $301 \mathrm{~nm}$. The measured areas $A$ were $1.4 \mu \mathrm{m}^{2}, 4.7 \mu \mathrm{m}^{2}, 9.0 \mu \mathrm{m}^{2}$, and $15.6 \mu \mathrm{m}^{2}$. The charge stored on the capacitor is distributed across a certain depth that adds the depletion series capacitance $C_{\text {depl }}$ in series to $C_{\text {ox }}$. The capacitance was estimated to be proportional to the area $A$ of the metallic electrode and inversely proportional to the depleted zone depth $d_{\text {depl }}$ according to

$$
C_{\mathrm{depl}}=A \frac{\varepsilon_{0} \varepsilon_{\mathrm{rSi}}}{d_{\mathrm{depl}}}
$$

with $d_{d e p l}=\sqrt{2 \varepsilon_{0} \varepsilon_{r} \Psi / q N_{A}}$ and where $\varepsilon_{\mathrm{rSi}}=12$ is the relative permittivity of the silicon bulk substrate, $\Psi$ represents the interface band bending at the $\mathrm{Si} / \mathrm{SiO}_{2}$ interface and is set to $200 \mathrm{mV}, q$ is the charge of the electron $\left(1.6 \times 10^{-19} \mathrm{C}\right), N_{A}$ is the doping level of the silicon bulk around $8 \times 10^{15} / \mathrm{cm}^{-3}$. From relations (1) to (3), we derive in TABLE I the theoretical capacitances data for respectively the smallest area of the gold pad $\left(1.4 \mu \mathrm{m}^{2}\right)$ and the largest one $\left(15.6 \mu \mathrm{m}^{2}\right)$. In particular, $C_{\text {ox }}$ is also calculated by finite element modeling using $\mathrm{COMSOL}^{\mathrm{TM}}$ to take into account the deviation from ideal capacitance induced by the fringing fields.
TABLE I THEORETICAL REFERENCES CAPACITANCES OF THE MOS CALIBRATION SAMPLE.

\begin{tabular}{|c|c|c|}
\hline \multirow{2}{*}{$d_{\text {ox }}(\mathrm{nm})$} & Capacitances \\
\hline \multicolumn{3}{|c|}{$\boldsymbol{A}=\mathbf{1 . 4} \boldsymbol{\mu m}^{\mathbf{2}}$} \\
\cline { 2 - 3 } & $C_{\text {ox, eq. (2) }} / C_{\text {ox,COMSOL }}-C_{\text {dep }}$ & $C_{\text {TOT }}[\mathrm{fF}]$ \\
\hline 41 & $1.18 / 1.28-0.47$ & 0.34 \\
\hline 127 & $0.38 / 0.48-0.47$ & 0.24 \\
\hline 220 & $0.22 / 0.32-0.47$ & 0.19 \\
\hline 301 & $0.16 / 0.26-0.47$ & 0.17 \\
\hline \multicolumn{3}{|c|}{$\boldsymbol{A}=\mathbf{1 5 . 6} \boldsymbol{\mu m}^{\mathbf{2}}$} \\
\hline 41 & $13.14 / 13.48-5.19$ & 3.74 \\
\hline 127 & $4.24 / 4.58-5.19$ & 2.43 \\
\hline 220 & $2.45 / 2.79-5.19$ & 1.81 \\
\hline 301 & $1.79 / 2.13-5.19$ & 1.51 \\
\hline
\end{tabular}

\section{MEASUREMENTS}

The measurements were performed around $9.95 \mathrm{GHz}$ using a 25PT300A AFM tip from Rocky Mountain Nanotechnology ${ }^{\mathrm{TM}}$. The RF power source is set to $0 \mathrm{dBm}$ and the intermediate frequency bandwidth (IFBW) of the VNA is $100 \mathrm{~Hz}$. The images were scanned over a $50 \times 50 \mu \mathrm{m}^{2}$ with 256 pixels at a scan rate of 0.625 line/s. In addition to the topography image (Fig. 2), the NSMM provides both magnitude and phase images of the complex reflection coefficient $\Gamma$.

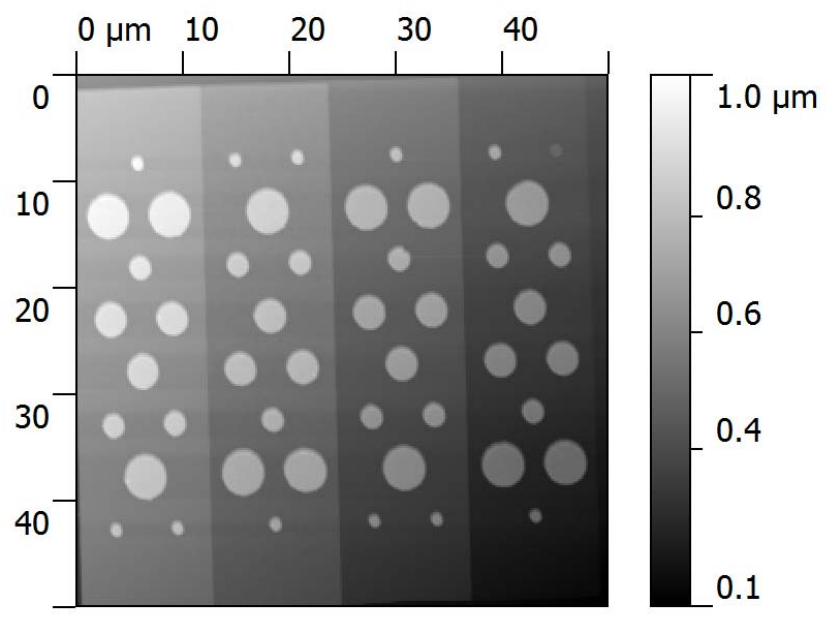

(a)

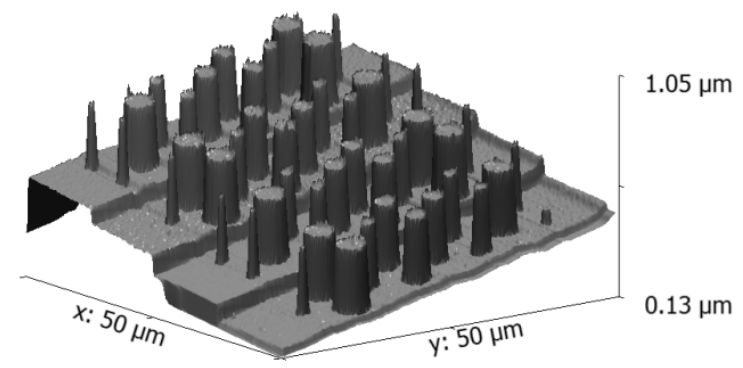

(b)

Fig. 2. NSMM topography image in (a) $2 \mathrm{D}$ view and (b) 3D view. 
After data leveling using Gwyddion ${ }^{\mathrm{TM}}$ software, tilt effects are corrected. Topography images for the smallest capacitors are given in Fig. 3. Although the capacitors are located on the upper and lower parts of the verification kit (Fig. 1), good agreement in the measured topography is noticed. Furthermore, the thicknesses of the $\mathrm{SiO}_{2}$ are identical at the different Y-locations.

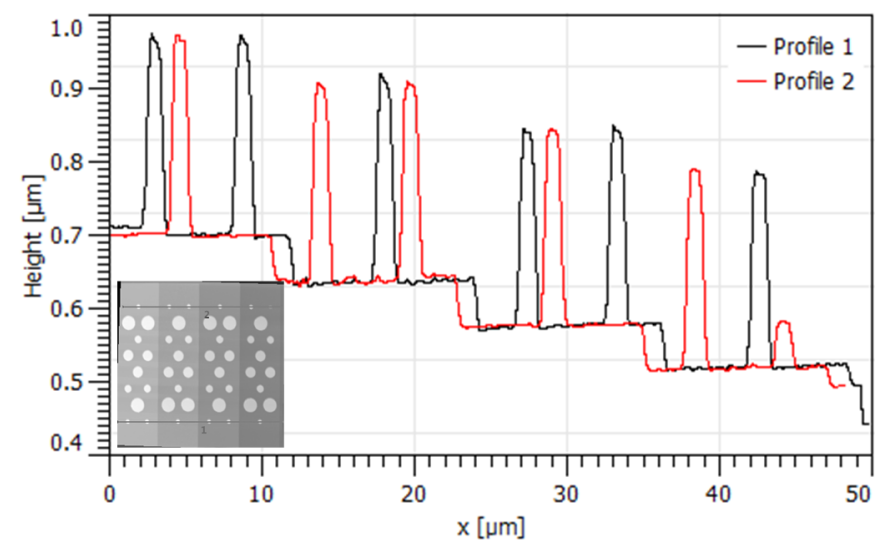

Fig. 3. 1D topography X-scans for the smallest capacitors.

The microwave image of the magnitude of the reflection is given in Fig. 4(a). The raw data shows a linear drift only for the Y-direction. This latter is mainly attributed to the VNA measurement configuration that is resynchronized with the topography image line by line. Consequently, a step line correction is applied to resynchronize the data [Fig. 4(b)]. Same findings are obtained for the phase-shift image, i.e. phase-jumps in synchronization can be corrected (Fig. 5).

Second step was to verify a possible correlation of the signals fluctuations between topography and microwave data. As illustrated in Fig. 6, the 1D scan regarding the capacitor indicated non-correlated fluctuations between topography and microwave signals. Therefore, fluctuations on the microwave signals are mainly attributed to the source and receiver noises of the VNA. No matching strategy is considered in this study, resulting in relatively poor measurement sensitivity. Indeed, fluctuations in the microwave signals become predominant for the smallest capacitors.

Third step was to apply a vector calibration technique based on a modified SOL technique [11]. To that end, three theoretical capacitance values, obtained from FEM simulation, are considered as capacitances standards to derive the capacitance values at the tip apex of the probe. To lower the measurement uncertainty, the measured capacitance values for each case are obtained as the average capacitance calculated on the whole capacitor surface (see inset of Fig. 7). The calibrated capacitances are given in Fig. 7 as a function of their theoretical counterparts. From these data, we demonstrate that capacitance values down to $500 \mathrm{aF}$ can be measured accurately without matching network between the VNA and the probe. To lower the measurement uncertainty, the microwave path should be kept as low less as possible.

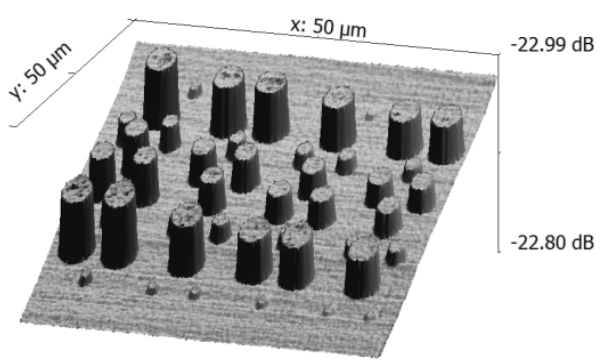

(a)

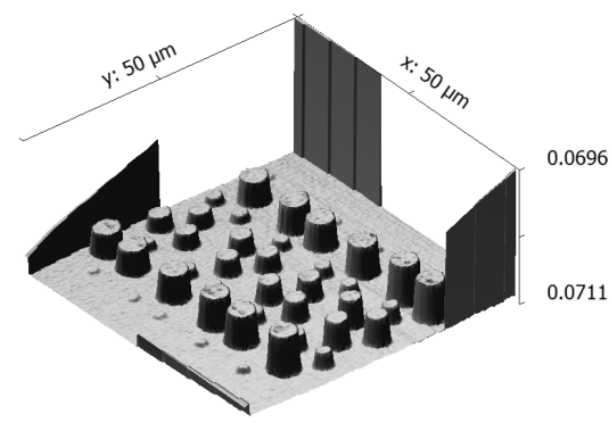

(b)

Fig. 4. 3D Image of the magnitude of the complex reflection coefficient $\Gamma$ (a) before and (b) after step line correction $\mathrm{F}=9.95 \mathrm{GHz}$.

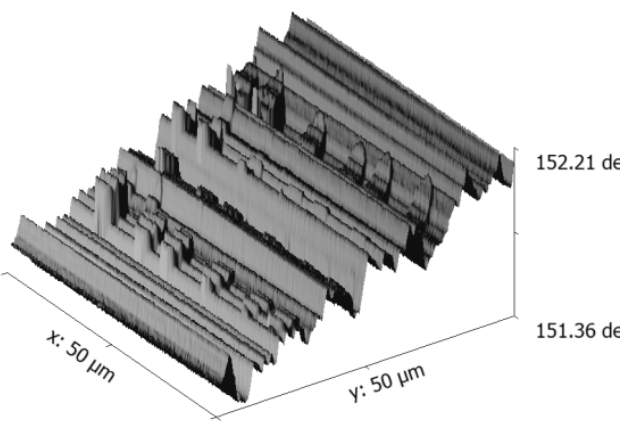

(a)

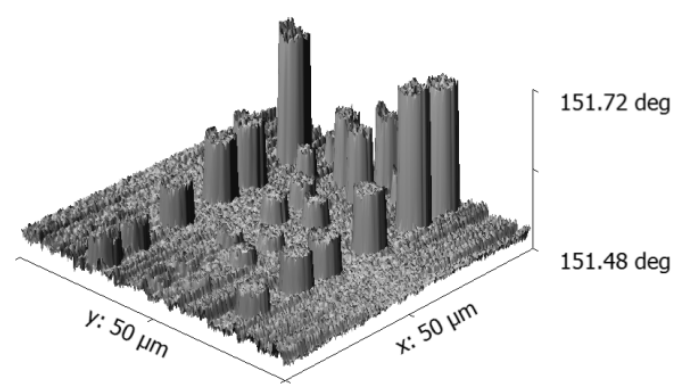

(b)

Fig. 5. 3D Image of the phase of the complex reflection coefficient $\Gamma$ (a) before and (b) after step line correction $\mathrm{F}=9.95 \mathrm{GHz}$. 

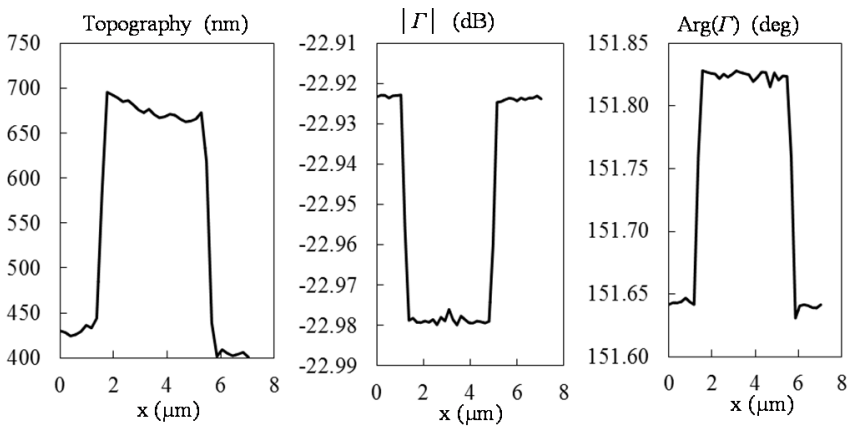

Fig. 6. 1D scan of a $2 \mu \mathrm{m}$-wide capacitor. (a) Topography. (b) Magnitude and (c) Phase of the reflection coefficient $\Gamma-\mathrm{F}$ $=9.95 \mathrm{GHz}$.

\section{Microwave capacitance (fF)}

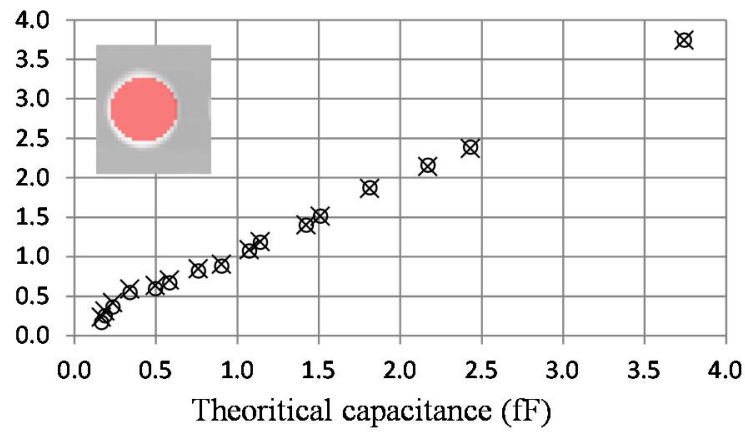

Fig. 7. Microwave capacitance as a function of the theoretical values $-\mathrm{F}=9.95 \mathrm{GHz}$. Two set of capacitances standards are considered.

\section{CONCLUSION}

Atomic force microscopy (AFM) image together with the magnitude and phase-shift images of the complex microwave reflection coefficient using a KeysightTM's LS5600 AFM interfaced directly with a vector network analyzer, without electrical matching strategy, are performed around $9.5 \mathrm{GHz}$. From a detailed analysis of the raw data, quantitative capacitances extraction indicates a limitation around $500 \mathrm{aF}$. Above $500 \mathrm{aF}$, noise effects are predominant and must be reduced. Strategies to enhance the measurement accuracy will be discussed in the final version of the paper.

\section{ACKNOWLEDGMENT}

This work is performed under EMPIR Planarcal project (http://www.planarcal.ptb.de). This work used the facilities within the EQPX ExCELSiOR (www.excelsior-ncc.eu) funded by the National Research Agency (ANR).

\section{REFERENCES}

[1] S. M. Anlage, V. V. Talanov, and A. R. Schwartz, "Principles of nearfield microwave microscopy," Scanning Probe Microscopy: Electrical and Electromechanical Phenomena at the Nanoscale, S. Kalinin and A. Gruverman, Eds. New York, Springer Sci., pp. 215-253, Aug. 2007.

[2] S. Fabiani, D. Mencarelli, A. Di Donato, T. Monti, G. Venanzoni, A Morini, T. Rozzi, and M. Farina, "Broadband Scanning Microwave Microscopy investigation of graphene", Proc. IEEE MTT-S International Microw. Symp., pp. 1-4, June 2011.

[3] G. Gramse, M. Kasper, L. Fumagalli, G. Gomila, P. Hinterdorfer and F. Kienberger, "Calibrated complex impedance and permitivity measurements with SMM," Nanotechnology, vol. 25, no. 14, p. 8, 2014.

[4] Agilent Technologies, Inc., "Scanning Microwave Microscopy (SMM) Mode", Datasheet, 2013.

[5] Oxford Instruments, Inc., "Scanning Microwave Impedance Microscopy (sMIM)", Datasheet, 2014.

[6] A. Imtiaz, T. M. Wallis and P. Kabos, "Near-Field Scanning Microwave Microscopy: An Emerging Research Tool for Nanoscale Metrology", IEEE Microwave Magazine, vol.15, no.1, pp.52-64, Jan. 2014.

[7] Olaf C. Haenssler et al, "Integration of a Scanning Microwave Microscope and a Scanning Electron Microscope: Towards a new instrument to imaging, characterizing and manipulating at the nanoscale", (3M-NANO), 2014 International Conference on. IEEE, 2014. p. 39-43.

[8] Olaf C. Haenssler and S. Fatikow, "Manipulating and characterizing with nanorobotics: In-situ SEM technique for centimeter and millimeter waves", In : Infrared, Millimeter, and Terahertz waves (IRMMW-THz), 2015 40th International Conference on. IEEE, 2015. p. 1-2.

[9] Zhang, Lan, et al. "Microwave atomic force microscopy imaging for nanometer-scale electrical property characterization." Review of Scientific Instruments 81.12 (2010): 123708.

[10] K. Haddadi, D. Glay and Tuami Lasri, A $60 \mathrm{GHz}$ scanning near-field microscope with high spatial resolution sub-surface imaging, IEEE Microw. Wirel. Compon. Lett., 21, no. 11, pp. 625-627, 2011.

[11] T. Dargent, K. Haddadi, T. Lasri, N. Clément, D. Ducatteau, B. Legrand, H. Tanbakuchi, and D. Théron, "An interferometric scanning microwave microscope and calibration method for sub-fF microwave measurements", Rev. Sci. Instrum., vol. 84, no.12, pp. 123705-123705-7, Dec. 2013.

[12] H. Happy, K. Haddadi, D. Théron, T. Lasri and G. Dambrine, "Measurement techniques for RF nanoelectronic devices : new equipment to overcome the problems of impedance and scale mismatch", IEEE Microwave Magazine, vol. 15, no. 1, pp. 30-39. Jan. 2014. 